\title{
FORMAL AND INFORMAL SUPPORT FOR PRETENURE FACULTY
}

\author{
RECOMMENDATIONS FOR ADMINISTRATORS AND \\ INSTITUTIONS
}

\section{Gwendolyn Mettetal, Gail M. McGuire Indiana University South Bend}

We analyze interviews from sixty-five faculty and administrators to understand the formal and informal types of support that pretenure faculty use to navigate their way to tenure. By understanding the different types of support that pretenure faculty need, institutions can better address the diverse issues that junior faculty confront when preparing for tenure and can ensure that all candidates receive some type of support. We conclude that institutions need to be intentional about offering both formal and informal support to pretenure faculty at various points in their careers.

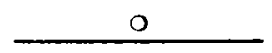

For most academics, the tenure decision is the most critical and anxietyproducing time in their career. Fortunately, there are many books with advice for pretenure faculty members, including suggestions on how to maintain scholarly productivity, be collegial, and balance competing demands (Diamond, 2004; Lang, 2005; Toth, 2009; Whicker,

We thank Indiana University South Bend for its financial support of this project. 
Kronenfeld, \& Strickland, 1993). Certainly tenure advice books for candidates are helpful, but they focus on the aspects of the tenure process that are largely under the control of the pretenure faculty member. Little scholarship offers guidance to the administrators who are supervising the tenure process and the institutions within which faculty are seeking tenure. We contend that many of the choices pretenure faculty members make depend on the options their institutions provide. Successfully navigating the tenure process therefore depends on both the individual choices that faculty members and the opportunities their institutions provide.

This chapter offers guidance to administrators and institutions on how best to support pretenure candidates as they progress toward tenure. Our case study identifies a range of formal and informal sources of support for pretenure faculty that an institution should consider offering. The multiple types of support we identify can assist institutions in addressing the diverse issues (balancing teaching, research, and service; documenting performance) that candidates face when preparing for tenure. We share both the strengths and weakness of the tenure support provided by our institution so that others can craft an effective portfolio of tenure support for their pretenure faculty. While pretenure candidates are responsible for meeting the standards for tenure in their institution, institutions also have a responsibility to inform candidates of these standards and offer them support in reaching them. This study is unique in focusing on recommendations to administrators and institutions and recognizing the importance of both formal and informal support for pretenure faculty members.

\section{Methods}

One of us (Mettetal) conducted an action research study on the support that faculty received as they worked toward tenure on our campus. Action research aims to address people's practical concerns (in this case, getting tenure) and contribute to broader knowledge in a collaborative research context (Griffiths \& Davies, 1993; Rapoport, 1970). Mettetal interviewed thirty-two of the forty-three faculty members who had received tenure in the past five years. Although the original focus of these semistructured interviews was a tenure dossier preparation group, the scope soon expanded to ask about all forms of support for achieving tenure. In addition, Mettetal interviewed five coleaders of the dossier preparation group and six administrators (deans, directors, and chairs), and held two focus groups with twenty-two pretenure faculty members. Interviewees represented a variety of disciplines, including arts, natural 
sciences, social sciences, education, business, and humanities. Interviews lasted an average of one hour and were audiotaped. The university's institutional review board approved both the original protocol and the revisions. Using qualitative methods that Glesne and Peshkin (1992) recommended, we both independently reviewed transcripts and looked for emergent themes. After discussion, we identified several major themes and then returned to the data to look for specific evidence of those themes. Although our suggestions are based primarily on these data, we also draw on Mettetal's eleven years of experience as a coleader of the tenure dossier prep group on our campus and the experience both of us have had as campus administrators.

Indiana University (IU) South Bend is a comprehensive public university in north central Indiana and the third largest campus in the IU system. The university has approximately eighty-three hundred students and offers over one hundred majors. The campus employs about 300 full-time faculty members and about 260 part-time faculty members. Tenure-track faculty members are generally required to spend 75 percent of their time teaching (three courses per semester).

\section{Results and Discussion}

Our research identified both formal and informal support for tenure on our campus. Sources of formal support included written documents, chairs and deans, formal mentors, a tenure dossier preparation group through the teaching center, third-year feedback from the academic senate tenure committee, new faculty orientation, and participation on a tenure committee. Sources of informal support included senior faculty members and peers.

\section{Formal Support for Tenure}

Our campus provides a number of formal sources of support to pretenure faculty ranging from a faculty handbook to a tenure preparation group. Faculty in our study were generally aware of these formal sources, but the helpfulness of each source varied with individual circumstances.

WRITTEN DOCUMENTS When new faculty arrive on campus, they are given documents that discuss tenure procedures and expectations. Sections of the IU and the IU South Bend academic handbooks describe policies and procedures and also provide an outline of materials that must be included in the tenure dossier. In addition, new faculty receive copies of 
their unit tenure expectations, which are more specific. According to our interviewees, these documents were useful in preparing a tenure dossier. For example, one faculty member said, "I got the faculty handbook, and somebody pointed out a list to follow-that list as you start to put together your dossier, and I did that from my very first submission." Another interviewee noted, "One of the nice things about our department is that we have a document that outlines what is considered excellence in teaching, what is considered excellence in research ... We have a very clear departmental document." In sum, formal tenure documents were useful for identifying the general contents of dossier and in some cases for articulating standards for excellence.

About half of the faculty members we interviewed were in units that ask for a complete dossier for each reappointment, which occurs almost every year. Several of those faculty mentioned that they used the same outline for their tenure dossiers that they did for their reappointment dossiers, which helped them keep materials organized. A unit's process for reappointment therefore can also influence the difficulty or ease of preparing a tenure dossier.

CHAIRS AND DEANS Department chairs (or deans in smaller units) were another source of formal support for pretenure faculty in our study. Faculty members are formally reviewed by their chair every spring based on their annual report of accomplishments in teaching, scholarship, and service. Faculty are also reappointed approximately once a year, and although reappointments go through all of the levels of a tenure decision, the most detailed feedback usually comes from the department chair. (In one unit, the unit's promotion, tenure, and reappointment committee provides that detailed feedback to the candidate.) If the chair takes this role seriously, these multiple opportunities for feedback and discussion can play a key role in helping junior faculty members build a strong case for tenure. Chairs can also use this occasion to offer guidance, provide resources, and point out opportunities that will benefit the pretenure faculty member. One professor remarked, for instance, "l got a lot of good information from my annual reviews from the school's tenure committee." The committee gave detailed feedback on his strengths and weaknesses and suggested actions he could take to strengthen his case for tenure.

Not all interviewees had supportive chairs or deans. In some cases, the problem was a lack of mentoring and social skills or benign neglect. In other instances, candidates reported having adversarial relationships with their supervisors. According to one interviewee, "I've had these pretty 
vocal arguments with the chair, so he might have reappointed me with reservations . . . and then $I$ understand that he instructed my dean not to reappoint me the year before my tenure." Another interviewee was in a unit with an unsupportive dean. When that dean left the year before the tenure decision, a professor from a different unit stepped in as interim dean. The interviewee said, "I believe God sent him to me! He had the experience; he knew exactly what needed to be done, when; what we needed. You don't have to know the discipline to mentor someone to tenure. You have to know academia. You have to know the system." This interim dean explained exactly what was going to be needed for tenure, including teaching documentation, scholarship, and external letters.

FORMAL MENTOR Chairs and deans can be important formal sources of support if they are competent and have a good relationship with the candidate. Because an institution cannot always assume either of these, it is important to have other formal mentors available to candidates. Mentors are "individuals with advanced experience and knowledge who are committed to providing support and upward mobility to their protégés' careers" (Ragins, 1999, p. 349). In a formal mentor program, individuals are assigned to each other, some official expectations of the relationship are communicated, and the relationship has a limited duration (Baugh \& Fagenson-Eland, 2007).

The history of formal mentoring on our campus offers a cautionary tale about how to make formal mentor programs effective. For many years, each unit on our campus assigned senior faculty as mentors for incoming faculty. When the University Center for Excellence in Teaching (UCET) was founded, it took over that responsibility, but three years later, the deans took back this task. In the following years, assignment of mentors was erratic, depending on the unit. UCET continues to arrange mentors for any faculty who request one, which helps fill the gaps. These formally assigned mentors could be very useful in explaining campus culture to new faculty, but according to our interviewees, they were not very helpful when it came to tenure issues.

Although some of the interviewees reported that formal mentors were helpful, most interviewees did not get much assistance from their mentors or were never assigned a mentor. On the positive side, a faculty member said, "I met with my mentor and got some honest feedback. Umm, some really good suggestions." This faculty member was encouraged by her mentor to collaborate with her new colleagues and to have a colleague observe her teaching, for instance. However, another interviewee said, "That faculty mentor position was very helpful to me my first semester in 
making that transition. But in terms of tenure, particularly because he had gone up for tenure a long time ago . . . Umm, I wasn't really looking for people who had gone ten or twenty years ago."

Inconsistent and unclear expectations for formal mentors likely explain the variation in their helpfulness with tenure. When UCET assigned mentors, a mentor training workshop discussed the needs of new faculty members and best practices in mentoring. Campus units, in contrast, did not provide that structure. The result was often benign neglect by the formal mentor, as one interviewee noted: "The mentor was always available to me and was always interested in answering my questions, but the mentor didn't necessarily seek me out to just kind of check in with me or to, you know, share some ideas that he might have had. So I had to make the effort to go by and say what about this, or explain this to me and so, I mean, he was very willing to do that, but I had to instigate it."

Another problem with our formal mentor structure was in how mentors were assigned to junior faculty members. The usual unit practice was to assign one of the most senior faculty in a unit as a mentor, but that person might not be the best choice. Senior faculty may be too busy, too removed from the tenure process, or not interested in fulfilling this role. Finally, because most senior faculty on our campus are white, they might not understand the challenges of the increasingly diverse junior faculty (Bowman, Kite, Branscombe, \& Williams, 1999).

UCET TENURE DOSSIER PREPARATION GROUP Our campus teaching center, UCET, sponsors a group to assist faculty in tenure dossier preparation every year. Faculty are invited to join the group in the November before they submit their dossier. Co-mentors who are experienced in many aspects of the tenure process lead these meetings, which take place every two to four weeks until dossiers are submitted in mid-August. The agenda includes drafting and commenting on vita and teaching and research statements, providing information on the tenure process (e.g., time line, soliciting letters), and tips on the mechanics of dossier preparation (e.g., assembling dossier binders) not easily found elsewhere. Because group mentors and participants come from a variety of disciplines, they must explain their teaching and research to colleagues from other areas. These discussions are particularly helpful in clarifying teaching and research statements. The usefulness of joint reflection was highlighted in McBride and Voegele's (2012) description of a faculty learning community focused on tenure and promotion.

According to those who participated in the UCET group, the most important benefit of participation was not the actual information 
provided, but the interactive aspects of the group process. One participant commented, "The direct instruction was probably the least important part and the 'active learning' part was the part that I found invaluable." One of the major activities of the group is to give feedback on each other's materials, and the group format seems to be conducive to this process. According to one participant, "I think that the group format is beneficial not just for the social comparison but also to see that it puts the criticism of your dossier in the context of, well, everybody's getting criticism and it's all supportive and made it easier I think, as opposed to let's say if I'd had you and $X$ helping me and say 'there's this problem with your dossier.'" Other benefits of participation interviewees mentioned were relieving stress, making new friends, and providing a time line and deadlines.

Not all participants found the UCET group helpful. Sometimes one or two highly anxious group members would monopolize the sessions, and their anxiety could be contagious. Several participants did not like the interdisciplinary nature of the group because they thought the discussions about teaching and research in other disciplines were not relevant to them. Finally, comments suggest that in some years, the group was too unstructured and consequently not very helpful. However, these comments tended to come from the people who had attended only a few of the sessions. Of those who did not attend the group, half said that they either felt that they knew what they were doing or that they already had quite a bit of help from other sources. Others mentioned time conflicts or other factors as reasons for not attending.

THIRD-YEAR FEEDBACK FROM ACADEMIC SENATE TENURE COMMITTEE OUr faculty handbook states that faculty in their third year can submit a dossier to the senate promotion, tenure, and reappointment committee (our campus PTR committee) and receive feedback about progress toward tenure. The dossier is usually assigned to one or two members of the committee for confidential feedback. Of those who took advantage of this option, most thought it was useful, especially if the candidate had no other source of feedback before tenure. One person said, "That was very helpful, and l've encouraged everybody to take advantage of that ... It seems like you got a letter which gives you a limited amount of information, and then you can contact the person for a meeting. And it's the meeting that's always more helpful." During the meeting, some PTR members gave detailed feedback on the candidate's progress toward tenure, as well as dossier organization. One interviewee mentioned that the third-year review was an impetus to begin working on the tenure dossier early. 
Like formal mentoring, however, the quality and quantity of feedback from the PTR committee varied widely, depending on who was on the committee. "I think a third-year review might or might not be useful depending on the kind of feedback that you get," said one interviewee. Based on our own experience, we know that the PTR committee did not always know they were supposed to offer this service. In fact, one year the committee sent the notice of this service out so late that candidates did not have time to compile a dossier. A handful of faculty members also said that compiling a dossier for the third-year review took too much time and effort. One said, "I took a look at that, and the thought [was] that it looked onerous or worrisome or too much for me to think about." Faculty members in our sample who decided not to participate in a thirdyear review were from units that did not turn in a complete dossier for reappointments, so they would be assembling a dossier from scratch. In units requiring a reappointment dossier, it was very easy to submit a midcareer dossier to the senate PTR committee.

NEW FACULTY ORIENTATION The University Center for Excellence in Teaching provides an orientation for new faculty, and most new faculty attend all or most of the sessions. The format has varied widely, from an intensive week to several days spread out over several weeks, but it always includes a brief discussion of the tenure process. One popular feature of the orientation is a panel discussion by pretenure faculty in their second or third year. They speak on many issues, from teaching concerns to setting up a laboratory to work/life balance, but they always mention thinking ahead to tenure. The main point they make about tenure is that faculty must begin documenting their teaching, research, and service early in their careers. A few interviewees recalled that the orientation urged them to save datebooks, syllabi, thank you letters, and other documents that they could eventually use to document their contributions.

PARTICIPATION ON A TENURE COMMITTEE Several interviewees mentioned serving on or observing a promotion and tenure committee as useful in preparing a dossier. At our institution, we recognize that PTR service can be helpful to junior faculty members, and chairs often suggest to junior faculty members that they serve a term on a PTR committee before going up for tenure. One faculty member said that serving on his unit's PTR committee helped him better understand the personalities in his unit: "You understand people a little better when you hear [them] vocalize their thoughts and you see a particular spin they might be interested in and how they look at things." Other faculty members explained that serving on a PTR committee helped them see what committee members pay attention 
to and how they evaluate materials. For instance, one junior faculty member said that she did not realize the importance of annual reports until she served on a PTR committee. Finally, one interviewee said that serving on a PTR committee taught her how to write for a general audience: "I think probably amongst the most useful things I got out of being on the PT\&R Committee . . . was to realize just how little people outside my field understand not just the gory details of what it is 1 do but the whole culture of how my kind of science operates." Finally, serving on a PTR committee gave pretenure faculty the opportunity to review many dossiers—good and bad. Candidates reported that it was helpful to know that there was not just one right way to put a dossier together, but that there were also certain practices that made a dossier ineffective or unimpressive.

\section{Informal Support for Tenure}

While IU-South Bend has a fairly extensive system of formal support for tenure, the participants in this study took advantage of informal sources of support as well. Senior colleagues within the university were the most common source of informal support, followed by peers within the university.

SENIOR FACULTY MEMBER Although the university handbook and departmental documents describe the general contents of the tenure dossier, they cannot possibly list all items that might be included in a dossier. Senior colleagues helped to fill this gap by informing candidates what materials to keep and how to document teaching, research, and service. For instance, one junior faculty member described how a senior colleague told her to document everything she did. Based on the authors' experience, this was good advice because when a junior faculty member starts on the tenure track, she or he might not be completely certain about her or his area of excellence. For instance, when one of our colleagues started on the tenure track on our campus, she had assumed that her area of excellence would be research. However, when her research articles took longer than expected to get published, she was grateful for the senior faculty member who encouraged her to document her teaching excellence because she declared teaching as her area of excellence for tenure.

Formal PTR documents typically do not describe different strategies to employ in creating a dossier, in particular, how to categorize one's research, teaching, and service activities (e.g., does a teaching publication go in the research or teaching section of the dossier?). Senior faculty made their own tenure dossiers available to candidates so that they could envision how to organize a dossier, demonstrate excellence, and write for 
a general audience. These colleagues also helped junior faculty understand and navigate the informal PTR guidelines. One interviewee obtained feedback from senior colleagues on what she called "the hidden rules about what counts as service at IUSB and what counts as scholarship." These rules are not in the handbook or formal PTR guidelines, but rather are determined by the culture of each academic unit. Finally, senior faculty helped pretenure faculty view their dossier from the perspective of their evaluators. One junior faculty member said that a senior colleague told him what people on PTR committees looked for and how they evaluated dossiers.

Senior colleagues also gave pretenure faculty copies of their annual reports for review and offered advice on what to put in their annual reports. These evaluations are foundational documents in the dossier because they are the record of one's yearly progress toward tenure. It is in these reports that faculty begin to build their case for excellence in research, teaching, or service. It would be extremely difficult to claim excellence in teaching for tenure, for instance, without documenting one's teaching activities and development every year.

Some pretenure faculty reported being anxious about how to put the actual dossier together-how to organize it, format it, what tabs to use, and so on. Senior colleagues demystified this aspect of the tenure process by helping candidates with these nuts-and-bolts issues of the dossier. For instance, one interviewee reported that two senior colleagues "talked about what they did and how long it took them and what they spent the most time on." Another senior colleague described "what was in his dossier and how he did it and how he thought about it." This information made the junior faculty member feel more confident that she would not "set off any red flags."

Senior faculty also helped junior colleagues by reviewing their dossiers. Their attention helped untenured faculty members identify what was missing from their dossier and what was unnecessary for it. One faculty member explained that a senior colleague helped her include "invisible labor," such as teaching outside the classroom and noncommittee service. In some cases, senior colleagues also edited dossier statements. One interviewee said this was particularly important for her because English was her second language.

The encouragement of senior colleagues was an important aspect of informal support in the tenure process as well. For instance, a senior colleague told one interviewee, "You've done these good things . . . don't feel nervous about this. You know this [going through tenure] is an opportunity for you to reflect." Another junior faculty member said, "One 
of the reasons why I got plenty of good nights' sleep over the process is just that I really simply had helpful and supportive senior colleagues who made it clear for me ... that they had confidence in me." Similarly, one untenured faculty member said, "I feel like they [senior colleagues] want you to succeed and they're very supportive. The expectation is that you will succeed." Encouragement from senior faculty who had survived the tenure process helped to decrease pretenure faculty members' anxiety and instill confidence in them at this vulnerable time.

Among the interviewees who relied on senior colleagues for help was a small subgroup who considered their senior colleague mentors. An interviewee with a vulnerable tenure case (she had little support from her chair and dean) said that her mentor had stood up to the administration on her behalf and told them that the junior faculty member was being treated unfairly. According to the interviewee, "Had she not done that, I probably wouldn't have gotten promoted." Another interviewee described the help she received from her mentor on the politics of the PTR process: "Another thing that was important about her mentoring is she has such a good sense of the ins and outs of this university, the politics. She's been on the PTR committee." One faculty member described how his mentor took him and a few other junior faculty "under her wing" and told them what to do and what not to do in regard to the different people in their unit. He said that his mentor warned him, "Be careful, don't step on this land mine, don't say too much about that because $\mathrm{X}$ doesn't like it." In other words, his mentor helped him navigate the political landscape in his academic unit.

PEERS The most common type of support that peers gave to each other was emotional and social. Some faculty members said they took comfort knowing that their peers were experiencing similar hardships and anxiety. For example, one interviewee said that it felt good knowing "that you're not the only person going through this pain and suffering ... Misery likes company, and it felt good that you're not the only one walking the halls on the weekends."

According to our data, peers often served as sounding boards for pretenure faculty, which helped the latter interpret tenure expectations. One candidate and a few other pretenured faculty members in his unit formed an informal support group to exchange ideas about what to include in the dossier. Another pretenured person said that she and a peer, who came from work backgrounds different from those of many of her other colleagues at the university, talked a lot about "the different cultural expectations" in their old and current work environments. 
In some cases, peers assisted each other with the statements in their dossiers as well. One faculty member described a lot of informal interaction (e.g., meeting for coffee) among the untenured folks in his unit and that he "picked up on things just from those kind of discussions." His peers sat on different committees, including PTR, and shared information from those experiences that helped him write his statements for a general audience. Another interviewee asked a junior faculty member in her department to read her research statement. She said, "I was concerned about my research statement being intelligible to people completely outside the field." She felt that if this person could understand her research statement, then others outside of her area probably would as well.

\section{Conclusion}

Pretenure faculty members differ in their strengths, needs, and willingness to use available resources. Units also differ in regard to the types of support they offer pretenure faculty members. Given all of these variables, institutions should create a wide web of support for pretenure faculty, including formal and informal sources. While formal documents provide the general framework for tenure and dossier preparation, informal mentors and peers help candidates navigate the politics of tenure, clarify expectations for their units, and provide emotional support. Building this kind of web will decrease the likelihood that a candidate will fall through the cracks. This case study also highlights the need to offer support to pretenure faculty at various points in their careers. Faculty orientations and tenure documents can be important in introducing ideas to junior faculty early on that chairs, mentors, and dossier support groups can later reinforce. While many of the faculty in our study reported more benefits from informal than formal sources, it is critical to offer formal sources of help for faculty who have unsupportive supervisors or work in hostile environments.

Whatever sources of support that institutions offer to pretenure faculty, they need to be intentional about how they do it. For instance, if institutions want chairs to be primarily responsible for guiding pretenure faculty through the tenure process, they need to communicate this expectation to chairs and prepare chairs to provide this support. They should also ensure that mentoring junior faculty is one of the criteria on which chairs are evaluated. If an institution decides to institute a formal mentor program, it needs to carefully consider program design, including training, structures of accountability, and communication of expectations (Lottero-Perdue \& Fifield, 2010). 
Our interviewees reported that informal sources of tenure support were more beneficial than formal sources, which suggests that institutions need to pay particular attention to the social climate on their campus. Administrators cannot make people like each other, of course, but they can create opportunities that will increase the likelihood that informal bonds will develop between faculty members. For instance, an all-day or overnight retreat could allow faculty to have more in-depth conversations than they would in the hallway. We recommend holding a retreat in a location with leisure activities available, such as walking, golfing, swimming, and having a glass a wine. Offering opportunities for faculty to share a meal or cup of coffee is another way to foster informal connections. When one of us (McGuire) was a junior faculty member, she was invited to attend a monthly gathering of faculty from her college at a local coffee house as well as a monthly ethnic potluck that drew faculty from across the campus. The relaxed nature of these occasions often led to off-the-record conversations about other faculty members and administrators, as well as explanations of how the university "really" operated. Finally, administrators should not underestimate the importance of physical space for fostering informal relations. We have faculty lounges scattered across our campus, which are often equipped with microwaves, refrigerators, coffee makers, and tables for eating. These amenities encourage faculty members to interact outside meetings regularly and create opportunities for personal conversations.

In sum, we recommend that institutions review the different sources of tenure support they offer junior faculty. While our results suggest that informal sources of support are more effective than formal sources of support, we recommend that institutions offer a variety of both types of support in order to meet the diverse needs of pretenure faculty. Being intentional about offering formal and informal support for pretenure faculty will help institutions create an effective web of support for junior faculty members as they work through the tenure process.

\section{REFERENCES}

Baugh, A. G., \& Fagenson-Eland, E. A. (2007). Formal mentoring programs: A "poor cousin" to informal relationships? In B. R. Ragins \& K. E. Kram (Eds.), The handbook of mentoring at work: Theory, research, and practice (pp. 249-271). Thousand Oaks, CA: Sage.

Bowman, S. R., Kite, M E., Branscombe, N. R., \& Williams, S. (1999). Developmental relationships of black Americans in the academy. In A. J. Murrell, F. J. Crosby, \& R. J. Ely (Eds.), Mentoring dilemmas: Developmental 
relationships within multicultural organizations (pp. 21-46). Mahwah, NJ: Erlbaum.

Diamond, R. M. (2004). Preparing for promotion, tenure, and annual review: A faculty guide (2nd ed.). San Francisco, CA: Jossey-Bass.

Glesne, C., \& Peshkin, A. (1992). Becoming qualitative researchers: An introduction. White Plains, NY: Longman.

Griffiths, M., \& Davies, C. (1993). Learning to learn: Action research from an equal opportunities perspective in a junior school. British Educational Research Journal, 19(1), 43-76.

Lang, J. M. (2005). Life on the tenure track: Lessons from the first year. Baltimore, MD: John Hopkins University Press.

Lottero-Perdue, P., \& Fifield, S. (2010). A conceptual framework for higher education faculty mentoring. In L. B. Nilson \& J. E. Miller (Eds.), To improve the academy: Resources for faculty, instructional, and organizational development, Vol. 28 (pp. 37-62). San Francisco, CA: Jossey-Bass.

McBride, L. G., \& Voegele, J. D. (2012). Reflecting together about tenure and promotion: A faculty learning community approach. In J. E. Miller \& J. E. Groccia (Eds.), To improve the academy: Resources for faculty, instructional, and organizational development, Vol. 30 (pp. 43-53). San Francisco, CA: Jossey-Bass.

Ragins, B. R. (1999). Gender and mentoring relationships: A review and research agenda for the next decade. In G. N. Powell (Ed.), Handbook of gender and work (pp. 347-370). Thousand Oaks, CA: Sage

Rapoport, R. (1970). Three dilemmas of action research. Human Relations, 23(6), 499-513.

Toth, E. (2009). Ms. Mentor's new and evermore impeccable advice for women and men in academia. Philadelphia: University of Pennsylvania Press.

Whicker, M. L., Kronenfeld, J. J., \& Strickland, R. A. (1993). Getting tenure. Newbury Park, CA: Sage. 